\title{
The role of the microbiome for human health: from basic science to clinical applications
}

\author{
M. Hasan Mohajeri ${ }^{1,2} \cdot$ Robert J. M. Brummer $^{3} \cdot$ Robert A. Rastall $^{4} \cdot$ Rinse K. Weersma $^{5} \cdot$ Hermie J. M. Harmsen $^{6}$. \\ Marijke Faas $^{7} \cdot$ Manfred Eggersdorfer $^{1}$
}

Published online: 10 May 2018

(c) The Author(s) 2018

\begin{abstract}
The 2017 annual symposium organized by the University Medical Center Groningen in The Netherlands focused on the role of the gut microbiome in human health and disease. Experts from academia and industry examined interactions of prebiotics, probiotics, or vitamins with the gut microbiome in health and disease, the development of the microbiome in early-life and the role of the microbiome on the gut-brain axis. The gut microbiota changes dramatically during pregnancy and intrinsic factors (such as stress), in addition to extrinsic factors (such as diet, and drugs) influence the composition and activity of the gut microbiome throughout life. Microbial metabolites, e.g. short-chain fatty acids affect gut-brain signaling and the immune response. The gut microbiota has a regulatory role on anxiety, mood, cognition and pain which is exerted via the gut-brain axis. Ingestion of prebiotics or probiotics has been used to treat a range of conditions including constipation, allergic reactions and infections in infancy, and IBS. Fecal microbiota transplantation (FMT) highly effective for treating recurrent Clostridium difficile infections. The gut microbiome affects virtually all aspects of human health, but the degree of scientific evidence, the models and technologies and the understanding of mechanisms of action vary considerably from one benefit area to the other. For a clinical practice to be broadly accepted, the mode of action, the therapeutic window, and potential side effects need to thoroughly be investigated. This calls for further coordinated state-of-the art research to better understand and document the human gut microbiome's effects on human health.
\end{abstract}

Keywords Microbiota $\cdot$ Gut $\cdot$ Prebiotics $\cdot$ Probiotics $\cdot$ Vitamins $\cdot$ Colonic fermentation · Inflammatory bowel disease $\cdot$ Irritable bowel syndrome $\cdot$ Gut-brain axis $\cdot$ Obesity

\section{Introduction}

M. Hasan Mohajeri

mhasan.mohajeri@uzh.ch; hasan.mohajeri@dsm.com

1 DSM Nutritional Products Ltd, Kaiseraugst, Switzerland

2 University of Zurich, Irchel, Zurich, Switzerland

3 Örebro University, School of Medical Sciences, Örebro, Sweden

4 Department of Food and Nutritional Sciences, University of Reading, Reading, UK

5 Department of Gastroenterology and Hepatology, University of Groningen and University Medical Center Groningen, Groningen, The Netherlands

6 Department of Medical Microbiology, University Medical Center Groningen, Groningen, The Netherlands

7 Department of Pathology and Medical Biology, University Medical Center Groningen, Groningen, The Netherlands
The University Medical Center Groningen (UMCG) in The Netherlands organizes annual symposia within the compass of medicine and nutrition, as part of its Healthy Ageing program. Previously published proceedings of these symposia have examined the relationship of nutrients with lifelong health and disease [1], with healthy aging [2], with malnutrition and obesity [3], and with nutrient-drug interactions [4].

The 2017 annual meeting at the UMCG focused on the role of the gut microbiome in human health and disease. The symposium, which brought together experts from academia and industry, examined interactions of prebiotics, probiotics or vitamins with the gut microbiome. The panel discussed the role of the microbiome on various aspects of healthy and diseased subjects throughout lifespan. In the context of disease, the symposia focused on two main intestinal conditions: inflammatory bowel disease (IBD), manifesting as 
Crohn's disease (CD) or ulcerative colitis (UC); and irritable bowel syndrome (IBS). Moreover, the various benefits of prebiotics on human health, the microbiome-nutrient interaction and the role of vitamins in promoting the selective growth of microbes in the gut as well as determinants of the development of a healthy microbiome were presented and discussed intensively. Last but not least, the panel discussed how the brain and the microbiome may affect and control each other's functions and the implications of such communication for treating or preventing the brain-related functional decline during aging.

It is worth noting that the terms microbiota and microbiome are frequently used interchangeably and this also applies here. Strictly speaking, however, microbiota is defined as the microbial taxa associated with complex organisms such as humans, whereas microbiome is the catalogue of these microbes and their genes [5]. The totality of data suggests great promise for use of pre- and probiotics in promoting general health and treating human diseases.

\section{Prebiotic interactions with the microbiome}

Dietary prebiotics have been defined as "a selectively fermented ingredient that results in specific changes in the composition and/or activity of the gastrointestinal microbiota, thus conferring benefit(s) upon host health" [6]. This definition has been subjected to debate as it focuses largely around the need for selective metabolism. An alternative definition which includes the mechanism of action has been established recently in a consensus statement [7]. The expert panel revised the definition of a prebiotic as "a substrate that is selectively utilized by host microorganisms conferring a health benefit". This updated definition still requires a selective microbiota-mediated mechanism to be defined as a prebiotic.

Fermentation of dietary prebiotics in the gut involves metabolic cross-feeding where the products of fermentation by one or more bacterial species provide the substrate(s) for other bacterial species (Fig. 1) [8]. This complex cooperative activity of the gut microbiota is essential for good health $[8,9]$. Bacterial fermentation of amino acids and proteins, which occurs mainly in the distal colon, generates a range of metabolites, many of which have a toxic potential. These include hydrogen sulphide, branched-chain fatty acids (BCFAs), phenol, indole, p-cresol, indoxylsulfate, p-cresylsulfate, and ammonia [10-12]. Even if also present in the healthy colon, it must be noted, however, that we currently have a very poor understanding of the concentrations of microbial metabolites in the human colon [12].

Several studies have demonstrated modulation of colonic microbiota by prebiotic inulin or inulin-type fructans. Realtime polymerase chain reaction (PCR) identification of selected bacterial species in the feces of human volunteers after inulin ingestion showed that the prevalence of Faecalibacterium prausnitzii and two Bifidobacterium species, B. adolescentis and B. bifidum, increased significantly [13]. In a placebo-controlled study, dietary inulin-type fructans increased the relative abundance of Bifidobacterium spp. and $F$. prausnitzii in obese women [14]. In healthy adults with mild constipation, inulin-type fructans increased the relative abundance of Anaerostipes, Bilophila and Bifidobacterium in feces, and reduced the abundance of Bilophila [15]. Differences in selectivity for the fermentation of several carbohydrate substrates (lactulose, galacto-oligosaccharides, sugar beet pectin and apple fiber) were found between the
Fig. 1 Fermentation and gut microbiota. The figure shows the principle sources of nutrition entering the human colon at the top and the principle metabolic outputs at the bottom. Arrows indicate known crossfeeding relationships between the principle microbial groups present. Metabolites in green boxes are believed to be healthpositive while those in red boxes are potentially harmful. Gaseous products are in orange boxes and the most significant intermediate products of metabolism are in blue

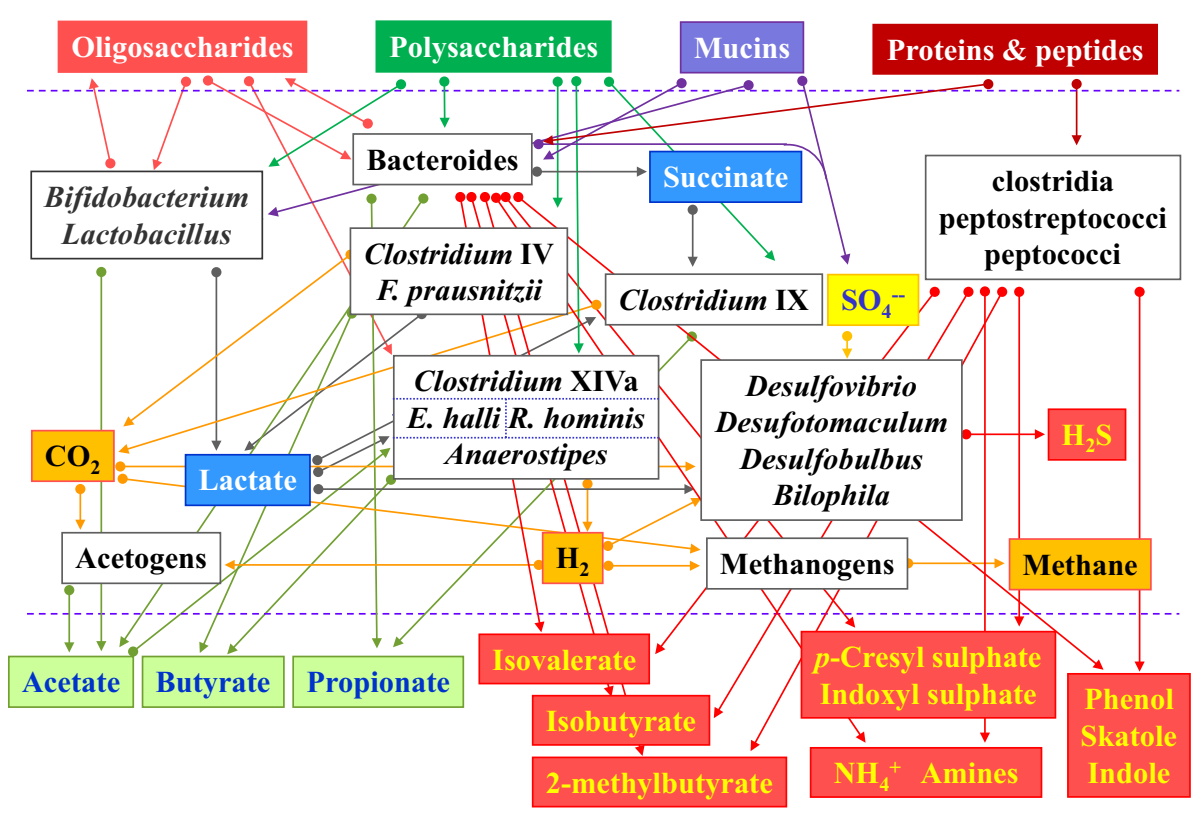


microbiotas from lean and obese healthy subjects using an in vitro model (TIM-2) of the proximal colon, providing the evidence that the composition of the microbiota changes depending on the body mass index (BMI) in humans [16].

Figure 2 summarizes the effects of prebiotics on human health. Several studies have examined the effect of prebiotics on allergic reactions and infections in infancy. A placebo-controlled randomized trial of infants with a parental history of atopy showed that formula milk supplemented with a prebiotic mixture of galacto-oligosaccharides (GOS) and long chain inulin significantly reduced the incidence of atopic dermatitis. Prebiotic supplements were associated with a significantly increased number of fecal bifidobacteria, but with no significant change in lactobacilli numbers [17]. In this same cohort of infants, the prebiotic supplemented milk significantly reduced the incidence of infectious episodes during the first 6 months of life [18]. In a 2-year follow-up study of this cohort, infants receiving prebiotic supplementation had a significantly lower incidence of allergic manifestations [19]. At 5-year follow-up, infants in the prebiotic supplementation group had a significantly lower incidence of any allergic manifestation and atopic dermatitis compared to the placebo group [20]. The proposed mechanism for this long-lasting effect of prebiotics is immune modulation mediated through changes in the intestinal microbiota [19]. In a three-group randomized intervention study, infants fed prebiotic GOS+inulin supplemented milk had comparable numbers of fecal bifidobacteria and lactobacilli to infants who were breast fed, whereas infants fed standard formula milk had significantly lower numbers of both bacterial genera. Incidence of gastrointestinal and upper respiratory tract infections was significantly lower in breast fed infants or the ones fed prebiotic supplemented milk compared to standard formula milk. Similarly, allergic reactions to food and milk were significantly higher in the standard formula milk group [21].

A meta-analysis of 26 randomized controlled trials (RCTs) involving 831 healthy adults showed that dietary prebiotic supplementation significantly increased selfreported feelings of satiety compared with placebo [22]. Healthy adults fed an oligofructose-enriched inulin diet experienced lowered hunger and increased satiety rates compared with the placebo, maltodextrin. The increased feeling of satiety was accompanied by an increase in plasma gut peptide concentrations of glucagon-like peptide 1 (GLP-1) and peptide $Y Y$ in prebiotic supplemented subjects, which may have contributed to the change in appetite [23], suggesting a potential for use in treating obesity. Similarly, in obese or overweight children, an oligofructose-enriched inulin diet significantly increased satiety compared with maltodextrin. Prebiotic supplementation led to a significant reduction in energy intake in older (aged 11-12 years), but not younger (aged 7-10 years) children [24] suggesting that prebiotic supplementation can potentially help to regulate energy intake in obese children.

Prebiotics have been used in several studies to treat constipation. A meta-analysis of RCTs involving 252 subjects (experimental group: $n=144$, control group: $n=108$ )
Fig. 2 Effect of prebiotics on gut function and health. The figure indicates likely mechanism of prebiotic action in the gut. In many cases the suggested mechanisms are speculative at the present time. Physiological functions are in purple and health outcomes are in green. Abbreviations: FFAR2/GPR 43, free fatty acid receptor 2; FFAR3/GPR41 free fatty acid receptor 3; GLP-1, glucagon-like peptide 1; GLP-2, glucagon-like peptide 2 ; IFN- $\gamma$, interferon gamma; IL-1 $\beta$, interleukin 1 beta; IL-6, interleukin 6; IL-10, interleukin 10; LPS, lipopolysaccharide; NK, natural killer cells; PYY, peptide YY; Th, T helper cells; TGF- $\beta$, transforming growth factor beta; Tr, T regulatory cells; ZO-1 zona occuldens protein 1

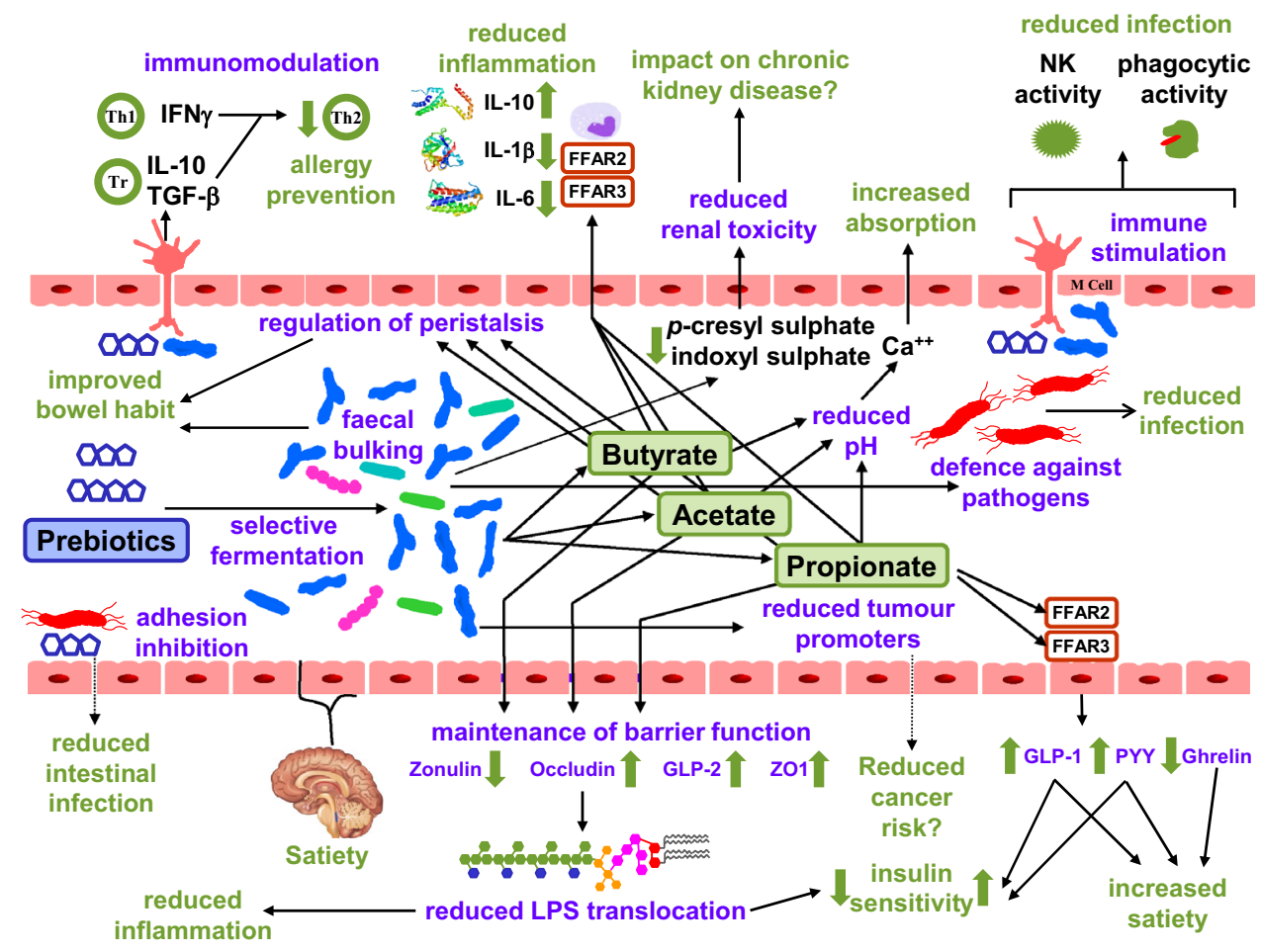


reported that inulin significantly improved bowel function in patients with chronic constipation exhibiting beneficial effects on stool frequency, the Bristol scale of stool consistency, transit time and stool hardness [25]. Following an evidence review the European Food Safety Authority (EFSA) concluded that "chicory inulin contributes to maintenance of normal defecation by increasing stool frequency" [26]. The results were recently confirmed in a randomized, placebocontrolled study showing that chicory inulin was effective in treating healthy subjects with constipation, increasing stool frequency significantly compared with placebo [27].

Additional described effects of prebiotics include reducing toxins produced from protein metabolism in urine ( $p$-cresol and ammonia) [28] and serum ( $p$-cresyl sulphate) [29], and increasing calcium absorption in adolescents [30, 31]. Prebiotics may also exert beneficial effects on host physiology which are independent of the microbiota as demonstrated by in vitro experiments for GOS. These included modulation of goblet cells to enhance mucosal barrier function [32], a direct protective effect on intestinal barrier function [33], and inhibiting adherence of enteropathogenic Escherichia coli to Caco-2 enterocyte and Hep-2 epithelial cells [34].

An improved understanding of the functional ecology of the gut and a more detailed knowledge of gut metabolites are particularly important for understanding the role of prebiotics on human health. For some products there is already good evidence on gut health and these findings should be communicated to health care professionals and consumers. On the other side, more studies on the effect of prebiotics on health outcomes in humans are imperative.

\section{The intestinal microbiome: a clinical perspective}

The human gut microbiota consists of trillions of microbes which form a complex ecosystem [35]. Although, some researchers have suggested that the number of microbes in the human gut is tenfold the total number of human somatic cells, a recent estimate has calculated that the numbers are of the same order, with the total number of bacteria in the human body being around $3.8 \times 10^{13}$ [36]. An aberrant gut microbiota has been described in several disorders including IBS, with exogenous factors such as antibiotics also causing disturbance of the intestinal microbiota [35].

The systemic effect of microbiota is mediated by microbial metabolites such as short-chain fatty acids (SCFAs), and the gases hydrogen sulfide, ammonia, hydrogen, methane, carbon monoxide and carbon dioxide [37, 38]. SCFAs, which comprise mainly acetate, propionate and butyrate, are produced under anaerobic conditions in the large intestine by fermentation of dietary fibers [37]. SCFAs activate the $\mathrm{G}$ protein-coupled receptors, GPR41/FFAR3 (free fatty acid receptor 3) and GPR43/FFAR2, which are present on multiple cell types including intestinal epithelial cells, macrophages, dendritic cells and mast cells [37, 39, 40]. Consequently, SCFAs have multiple effects on the host, including acting as an energy source, promoting glucose and energy homeostasis, regulating immune responses and inflammation, regulating anorectic hormones which have a role in appetite control, tumor suppression (especially butyrate), and regulating central and peripheral nervous systems [37, 39-42].

The effects of butyrate on the human colonic mucosa were examined following administration of butyrate enemas at physiologically relevant concentrations in healthy volunteers. Transcription analysis of microbiome revealed that butyrate induced differential expression of multiple genes involved in fatty acid oxidation, electron transport chain and oxidative stress pathways [43]. In addition, butyrate led to dose-dependent decreases in visceral sensitivity [44]. However, butyrate enemas administered to patients with UC in clinical remission had relatively minor effects on inflammatory and oxidative stress parameters, although the selection of patients with chronically mild levels of inflammation and oxidative stress may have limited the scope of this study [45].

Protection against microbial invasion is provided by the intestinal barrier [46]. The intestinal barrier has multiple lines of defense including commensal bacteria, which competitively inhibit the colonization of pathogenic bacteria and the production of metabolically protective compounds such as butyrate [46]. Impaired intestinal barrier function may result in a local or systemic immune response, mast cell degranulation, neuroinflammation and afferent vagus nerve activation [46]. In addition, commensal bacterial species such as Lactobacillus plantarum regulate intestinal epithelial integrity by stimulation of Toll-like receptor 2 (TLR2) in the gut epithelium [47]. In one study, extensive transcriptome analysis following consumption of three probiotic strains, Lactobacillus acidophilus, L. casei, and L. rhamnosus, by healthy volunteers showed that each species induced differential gene expression in networks involved in regulation of major basal pathways in the small intestinal mucosa, which resembled those induced by specific bioactive molecules and drugs [48]. The potential of probiotic bacteria to improve intestinal barrier function is discussed extensively in a recent review [49].

Investigation of intestinal barrier function and intestinal permeability can be done by using a so-called Ussing chamber, an ex vivo method that uses intestinal specimens. The multi-sugar test is a non-invasive method that measures urinary excretion of ingested sugars as a measure of gut permeability [50, 51]. Indicators for gastroduodenal and small intestinal permeability are sucrose excretion and 
the lactulose/rhamnose ratio in $0-5 \mathrm{~h}$, respectively. Colonic permeability is estimated by the sucralose/erythritol ratio from urine sampled 5-24 h after the sugar ingestion. Application of the multi-sugar test showed that small intestinal permeability was increased in patients with diarrheal IBS compared to healthy controls [50].

Patients with post-infectious IBS have reduced mucosal and fecal microbial diversity compared with healthy controls. In addition, the intestinal microbiota of post-infectious IBS patients was shown to be different from that of general IBS patients [52]. Differences between post-infectious IBS patients and healthy controls were also found with respect to release of immunoregulatory cytokines (IL-13, IL-10 and IL-1 $\beta$ ) following ex vivo stimulation of colonic biopsies with selected species of anaerobic commensal bacteria. These results are consistent with an altered immune response against commensal gut microbes in post-infectious IBS patients [53].

Therapeutic alteration of intestinal microbiota in conditions such as IBS may be achieved by ingestion of probiotics and prebiotics to increase the number of commensal bacteria within the gut, antibiotics which deplete pathogenic bacteria, and fecal microbiota transplantation (FMT) which introduces a healthy, diverse microbiota into the gut [35]. A meta-analysis of FMT reported that the method was highly effective for treating recurrent Clostridium difficile infection [54] and an expert consensus panel has recommended indications, technical procedures and clinical trial details of FMT for treating various conditions [55]. The panel also considered that, at the present time, FMT should be performed only in research settings for treatment of IBD, IBS and metabolic syndrome [55]. Further research is needed to establish the role of FMT for treating these disorders.

\section{Microbiome-nutrient interactions in the diseased gut}

LifeLines is a large prospective cohort study in The Netherlands that includes more than 165,000 individuals, representing three generations, with a proposed duration of 30 years. The study collects extensive data on participants including demographic, biological and phenotypic information including genetic, epigenetic and 'omics' data (metabolomics, transcriptomics, proteomics), with a wide range of biomaterials stored in a biobank. Subjects are required to complete a questionnaire each year, and several biomarkers are measured every 5 years [56]. LifeLines Deep is a cohort of 1500 individuals within LifeLines for whom multiple layers of omics information have been generated including both $16 \mathrm{~S}$ and whole genome metagenomic sequence data [57]. At the time of the symposium, full metagenomic sequence data was available from $\sim 1600$ population-based individuals including approximately 1100 of the LifeLines DEEP population [57] and $~ 500$ from the Functional Genomics Project [58, 59]. In addition, two disease focused cohorts are also available including 380 patients with IBD and 400 patients suffering from IBS [57, 60-63].

Genetic analysis of the human gut microbiota is commonly performed by high-throughput metagenomic sequencing and taxonomic profiling following analysis of $16 \mathrm{~S}$ ribosomal RNA gene sequences [64]. Full metagenomic sequencing of isolates enables not only taxonomic profiling, but also can gain insight at the strain level, and into functional parameters such as metabolic pathways and other biological processes, virulence factors, and antibiotic resistance. However, there is still a limited understanding of individual factors that shape the microbiota on individual level.

It is known that the overall diversity of the human gut microbiota changes throughout life, increasing steadily from birth until around 12 years of age, remaining relatively stable throughout adulthood, and then declining in later years [65]. In adults, $60-70 \%$ of the gut microbiome is stable, with the degree of stability varying between phyla [66]. Infections, lifestyle and dietary changes cause microbiome instability, producing major perturbations of the gut microbiome as nicely shown in a high-resolution longitudinal study in two individuals [67]. To study the role of the gut microbiome in health and disease, the scientific world first must address the question: what is a "healthy" microbiome and which factors influence the gut microbiome composition. For addressing this question and defining the intrinsic and extrinsic factors that influence the gut microbiome, Zhernakova et al analyzed the LifeLines Deep cohort utilizing metagenomic shotgun sequencing of the gut microbiome of 1135 participants and more than 200 phenotypic features. This study highlighted a relationship between the microbiome and multiple extrinsic and host factors, comprising 60 dietary factors, 31 intrinsic factors, 19 drug categories, 12 diseases, and 4 smoking categories. Together, these factors accounted for $18.7 \%$ of the observed inter-individual variation in the gut microbiome with diet being a major modulator of gut microbiome variation [63].

Multiple intrinsic factors that were associated with inter-individual variation in the gut microbiome included chromogranin A, a member of the granin family of neuroendocrine secretory proteins, stool frequency and Bristol classification of stool type but interestingly also triglyceride concentrations. Age and high-density lipoprotein (HDL) concentration were positively correlated with gut microbiome inter-individual variation [63]. In another study, our group showed by performing a Mendelian Randomization study that the human gut microbiota is an independent factor for variation of blood lipid levels, accounting for $6 \%$ of triglyceride, and $4 \%$ of HDL variance. In addition, we could 
show that $4.5 \%$ of the variance in $\mathrm{BMI}$ is attributable to the gut microbiome [68].

Analysis of the gut microbiome revealed that the use of proton pump inhibitors (PPIs) was associated with a significant decrease in gut microbiota diversity and with significant changes of around $20 \%$ of bacterial taxa. This adverse effect of PPIs on bacterial diversity was greater than for any other drug class, including antibiotics. PPIs depleted beneficial bacteria such as the Ruminococcaceae family and Bifidobacterium, and increased potentially harmful bacteria including Enterococcus, Streptococcus, Staphylococcus genera and Escherichia coli. Results suggested that PPIs diminished the gastric acid barrier, as species found in the oral microbiome of PPI users were more abundant in the gut than in non-users [61]. It is increasingly observed that the use of PPIs is associated with an increase in the incidence of enteric infections like Clostridium difficile and Campylobacter. Given the profound effect of PPIs on the gut microbiome and the fact that over $11 \%$ of population in The Netherlands and other European countries are using PPIs on prescription (not including over the counter use of PPIs) implies a major PPI-dependent influence on the gut microbiome taxonomy and function on a populational scale.

The Microbiome working group within the UMCG has embarked recently on a large project within the LifeLines cohort: the $10 \mathrm{~K}$ metagenome project. Full metagenomic sequence data will be generated from fresh frozen fecal samples of 10,000 individuals. In addition to the genetic data, more than 2000 phenotypic details will be available for each individual. It is planned that the subjects will prospectively followed up every 5 years.

Taken together, the population-based LifeLines cohort is providing valuable insight into the complex interaction of microbiome with human health and will be instrumental in outlining new biomarkers and treatments for human diseases.

\section{Effects of vitamins on the microbiome}

The human gut microbiota contains bacteria that are beneficial to the host, and bacteria with pathogenic potential, termed 'pathobionts' [69]. An important role of beneficial bacteria is the metabolic production of SCFAs by cross-feeding (Fig. 1). Fiber-degrading bacteria include Ruminococcus callidus, Ruminococcus albus, Blautia obeum and Prevotella spp. which produce solubilized oligosaccharides and polysaccharides that act as substrates for butyrate-producing species such as Faecalibacterium prausnitzii, Eubacterium rectale, Roseburia spp, Eubacterium hallii and Anaerostipes spp [37]. Butyrate has multiple effects on the host including maintenance of gut barrier function by stimulating the production of mucin, antimicrobial peptides, and tight-junction proteins and reducing colonic oxidative stress [70]. These effects on gut barrier function are important for health as changes in the mucosal barrier have been described in IBD [71].

Gut microbiota imbalance, or dysbiosis, is considered to play a significant role in the pathogenesis of intestinal disorders such as IBD and IBS, and of extra-intestinal disorders including allergies, asthma, type 1 diabetes, cardiovascular disease, metabolic syndrome, and obesity [72]. Chemotherapy-induced mucositis which occurs in the mouth and gut results from damage to the mucosal barrier and can result in bacteremia, which is the abnormal presence of bacterial in blood. It has been suggested that commensal intestinal bacteria may play a key role in amelioration of inflammation and bacteremia [51]. In a rat model of chemotherapyinduced mucositis, the number and diversity of the fecal microbiota was substantially decreased, including anaerobes and Streptococci, although there was a relative increase of Bacteroides [73]. Supporting the beneficial anaerobic microbiota during chemotherapy may, therefore, improve treatment and quality of life for cancer patients.

Faecalibacterium prausnitzii is a Gram-negative obligate anaerobe which is difficult to culture, and taxonomically is in the Clostridia order of Firmicutes (Fig. 3). It is present in the gut of all healthy humans and may act as a biomarker of a healthy gut [74]. Dysbiosis associated with CD is characterized by reduced abundance of $F$. prausnitzii [75], with dysbiotic ileal CD patients having a significantly lower abundance of $F$. prausnitzii and a concomitantly increased abundance of E. coli [76]. Mechanistically, animal experiments provide an explanation for the increased abundance of $E$. coli in IBD as

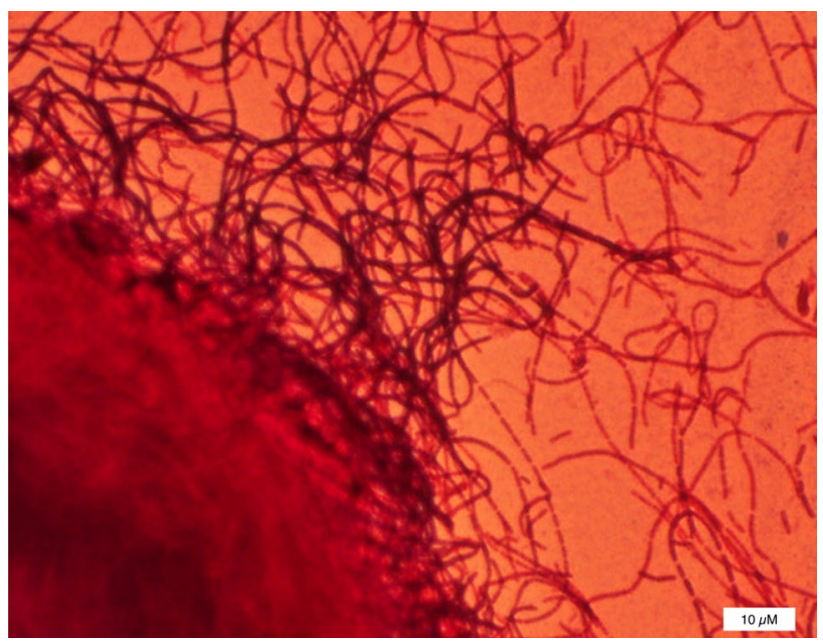

Fig. 3 A picture of the Gram-stained cells of Faecalibacterium prausnitzii growing in a colony inside agar seen as a big ball at the left lower corner, chains of cells grow away from this colony [80]. A typical single cell has the size of 3-5 $\mu \mathrm{m}$ in length and $1 \mu \mathrm{m}$ in diameter. The bar represents $10 \mu \mathrm{m}$ (Photo, M. Sadaghian Sadabad) 
nitrate, which was generated as a byproduct of the inflammatory host response, selectively enhanced growth of $E$. coli in the large intestine of mice [77]. Moreover, F. prausnitzii produces a $15 \mathrm{kDa}$ anti-inflammatory protein that inhibits the $\mathrm{NF}-\kappa \mathrm{B}$ pathway in intestinal epithelial cells and was shown to prevent colitis in a mouse model [78].

F. prausnitzii uses riboflavin (vitamin B2) as a mediator for extracellular electron transfer, as demonstrated in a microbial fuel cell system [79]. A Human oxygen-Bacteria anaerobic (HoxBan) co-culture system has been developed in which $F$. prausnitzii was cultured with adherent Caco-2 cells. Caco-2 cells promoted the growth and metabolism of the anaerobic $F$. prausnitzii, while genes involved in inflammation and oxidative stress in Caco- 2 cells were suppressed by $F$. prausnitzii [80].

Anti-oxidants including riboflavin and vitamin $\mathrm{C}$ are being investigated as new targets for intervention for the treatment of dysbiosis. A first pilot open-label study with $100 \mathrm{mg} /$ day riboflavin showed indeed an increase in faecalibacteria and a reduction in E. coli in most participants [81]. The double-blind, parallel-group, placebo-controlled Ribogut trial is currently examining the effect of 50 or $100 \mathrm{mg} /$ day riboflavin administered to healthy volunteers for 14 days on the gut microbiota composition with results to be expected in 2018 .

\section{Early-life development of a healthy microbiome}

The development of the perinatal gut microbiota is influenced by multiple factors including gestational age, mode of delivery, maternal microbiota, infant feeding method, genetics, and environmental factors such as the choice of food. Microbial diversity increases dramatically during first months of infancy (Fig. 4). At birth, the microbiota is aerobic, with low numbers and low diversity, with the most common bacteria facultative anaerobes and members of the Enterobacteriaceae phylum [82]. Within a few days, the gut environment becomes anaerobic resulting in growth of bacteria such as Bifidobacterium [82], which is the dominant bacterium genus in the infant gut in the first months of life. With the introduction of solid food, a more adult-like microbiome starts to develop as of 6 months of life, dominated by Firmicutes and Bacteriodetes [82].

Factors promoting a healthy microbiota in neonates include a vaginal delivery, delivery at term, breast feeding, and exposure to a variety of microorganisms. In contrast, a Caesarean section, premature delivery, formula milk, and exposure to antibiotics have a negative impact on the diversity and composition of microbiota in infants [25, 83-85].

Preterm infants show delayed colonization of the gut microbiota with Bifidobacterium, and have a high prevalence of Enterobacteriaceae, Staphylococcus, and Enterococcaceae [25]. Vaginally delivered neonates have an increased prevalence of maternal microbiota derived from the vagina and intestine (e.g. Lactobacillus, Prevotella and Sneathia) compared with neonates delivered by Caesarean section. Caesarean section delivered infants have a relatively high prevalence of skin bacteria such as Staphylococcus, Propionibacterium and Corynebacterium compared to the ones that are vaginally delivered [25, 84]. Maternal antibiotic treatment that results in reduced utilization of human milk and prolonged hospitalization normally causes an increased prevalence of Proteobacteria, Firmicutes, Enterobacteriaceae (E. coli and Klebsiella spp.), Staphylococcus, Propionibacterium and Corynebacterium [25]. Feeding formula milk is associated with increased bacterial diversity, increased prevalence of Bacteroides fragilis, Clostridium difficile, and E. coli, and a decreased prevalence of bifidobacteria [84].

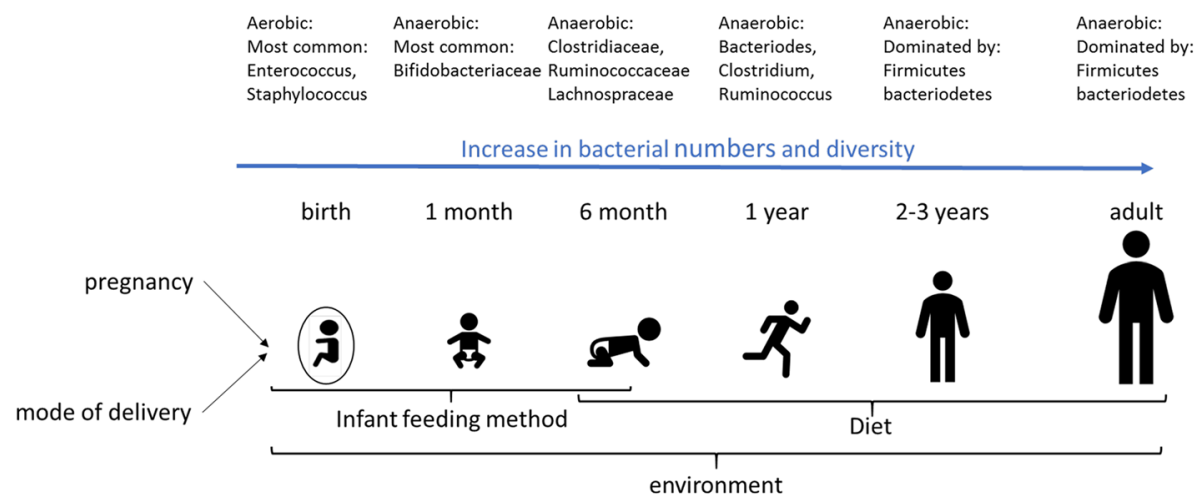

Fig. 4 Development of the gut microbiome during infancy. The development of the infant microbiome is dependent on various factors, such as infant feeding method, diet and the environment. Also, the mode of delivery (either vaginal or by cesarean section) affects the early life microbiome. Transfer of bacteria from the mother to the fetus has also been shown, indicating that pregnancy may be important for colonization of the fetal/infant gut 
As previously mentioned, dysbiosis in infancy is associated with an increased risk for immunological diseases such as asthma, allergic rhinitis, type 1 diabetes and celiac disease in addition to metabolic diseases, e.g. obesity and type 2 diabetes [84, 85].

Pregnancy is shown to alter the maternal gut microbiota. In humans, dramatic changes in the gut microbiota during pregnancy were described from the first to third trimesters with an overall increase in the relative abundance of Proteobacteria and Actinobacteria, and with a reduced richness with a decreased abundance of Firmicutes and Bacteroidetes [86]. In C57BL/6 mice, pregnancy produced significant increases in the relative abundance of genera including Akkermansia, Bacteroides, Bifidobacterium, and Clostridium, in comparison to non-pregnant females. Changes in the microbiota began at the onset of pregnancy [87]. Pregnant Balb/c mice showed significant increases in the relative abundance of Actinobacteria and Proteobacteria compared with non-pregnant littermates. The relative changes in gut microbiota of non-pregnant and pregnant mice were strain-specific suggesting that genetic background is an important determinant of the microbiome. The physiological changes that occur in pregnancy produces significant changes in maternal metabolism necessary for supporting a healthy pregnancy [86]. The mechanisms resulting in alteration of the microbiota during pregnancy are largely unknown, but it seems likely that microbiome alterations during pregnancy are also important to support changes in maternal immune status and/or hormonal changes $[86,88]$.

It has also been suggested that changes in the maternal microbiota during pregnancy are important for fetal health, since it has been shown that maternal microbiota can be transferred to the fetus [89]. The transfer of microbiota from the mother to the fetus can be observed in the meconium, which in contrast to the earlier beliefs is not sterile [89]. The microbiota of meconium has low diversity represented by the Firmicutes (Staphylococcus, Enterococcus, and Bacilli), Proteobacteria and Actinobacteria phyla, and low bacterial cell numbers [90]. Variation in the microbiota of meconium is affected by maternal diabetes status [91] and maternal gestational diet, with a high-fat diet producing pronounced changes in neonatal meconium which persisted in infant faces for up to 6 weeks of age [92].

Also, the human placenta is not sterile. Indeed, the placental microbiome is unique and is comprised of commensal bacteria from the Firmicutes, Proteobacteria, Bacteroidetes, Tenericutes, and Fusobacteria phyla, and has some similarity to the human oral microbiome [93]. Low diversity of placental microbiota was significantly associated with low birth weight in full-term neonates [94]. Inter-individual placental microbiome diversity (beta diversity) was significantly associated with prenatal infection or a preterm birth [93].
Direct evidence of transfer of maternal bacteria is derived from experiments in mice, in which oral administration of a genetically-labelled Enterococcus fecium strain to pregnant mice, resulted in a subsequent detection in meconium [89]. Furthermore, experiments of microbial colonization of pregnant germfree mice demonstrated that maternal microbiota affects neonatal immune responses. Gestational colonization had effects on the innate intestinal immune response of the offspring, with increased numbers of intestinal innate lymphoid cells (ILC3), macrophages and dendritic cells, in addition to an effect on intestinal gene expression including genes involved in pathways for sugar metabolism, epithelial cell division and proliferation, and mononuclear cell function [95].

The development of the neonatal microbiome is dependent on various factors. It is known since long that birth mode, feeding mode and antibiotic exposure, all affect the development of the neonatal microbiome. Since also treatment with pre- or probiotics may affect the neonatal microbiome, such treatments may be effective options to optimize development of the neonatal microbiome.

It has become clear that the fetus and placenta are not sterile and the transfer of bacteria occurs from mother to the fetus during pregnancy. Therefore, the maternal microbiome also seems to be important for the development of the neonatal microbiome. This implies that pre- or probiotics use may open a possibility to modulate the maternal microbiome during pregnancy, to optimize the development of the fetal microbiome. Further studies on the role of the maternal microbiome in development of the neonatal microbiome are necessary.

\section{Microbiome and the gut-brain axis}

The bidirectional signaling between the gut microbiota, the gut, and the brain occurs via neuronal pathways involving both the central and enteric nervous systems in addition to the circulatory system $[96,97]$. The latter includes involvement of the hypothalamic-pituitary-adrenal (HPA) axis, immune system regulators, hormones, bacterial metabolites such as SCFAs, and neurotransmitters [96, 98].

Preclinical studies have shown effects of the gut microbiota on nociceptive reflexes [99], feeding, emotional and social behavior [99], the stress response [99], and brain neurochemistry $[100,101]$. The gut microbiota is essential for normal social development in the mouse and is implicated in neurodevelopmental disorders including autism spectrum disorder [102-104]. Germfree mice have an exaggerated stress response compared with control animals. These mice also exhibit increased motor activity and lower anxiety-like behavior compared with control mice [105]. Administration of the probiotic L. rhamnosus (JB-1) to mice reduced 
stress-induced corticosterone levels and anxiety-related behavior [101]. These data strongly highlight the importance of the microbiome-gut-brain axis for normal neurological development and function.

Central control of the gut is mediated through the HPA axis and the autonomic nervous system. Preclinical studies on the stress response illustrate the effect of the CNS on the gut microbiome [97]. In primates, prenatal and postnatal stress affected the composition of the intestinal microbiota [106]. In addition to changes in the microbiome, postnatal stress was associated with stress-indicative behavior [106]. In rats, postnatal stress altered the fecal microbiome, with notable changes in behavior and immune status [107].

The mechanisms by which the gut microbiota exert their effects on the brain are beginning to be understood [97]. Circulating SCFAs produced by gut microbiota influence the integrity of the blood-brain barrier (BBB) by increasing production of the tight junction proteins claudin- 5 and occludin. This increased BBB integrity limits entry of undesirable metabolites into brain tissue [98]. Compounds collectively known as microbe-associated molecular patterns (e.g. lipopolysaccharide, bacterial lipoprotein, flagellin and $\mathrm{CpG}$ islands of unmethylated DNA) produced by the gut microbiota influence neuroimmune function by stimulating the release of cytokines such as TNF $\alpha$, IL- 6 and IL- $1 \beta$ from innate immune cells such as dendritic cells, macrophages and neutrophils. These cytokines can cross the BBB and activate microglia and neurons resulting in altered neurological function which can result in a change in mood and behavior [98].

A growing number of placebo-controlled RCTs have investigated the effect of probiotics on mood, cognition and brain function in humans. In healthy women, ingestion of a fermented milk product supplemented with probiotics containing Bifidobacterium animalis, subsp. lactis, Streptococcus thermophiles, and two Lactobacillus spp. produced significant changes in brain activity assessed by functional magnetic resonance imaging (fMRI), in response to an emotional faces attention task. Reduced fMRI reactivity was found in interceptive and somatosensory regions of the brain which control central processing of emotion and sensation [108]. Probiotics containing Lactobacillus helveticus and Bifidobacterium longum showed beneficial psychological effects in healthy human volunteers, with significant improvements in several global tests including the reduction of global psychological symptoms, depression and anxiety [109]. A probiotic milk drink containing Lactobacillus casei Shirota ingested by healthy volunteers had no effect on the mood of the group overall, but improved mood in subjects with low baseline mood, although an unexpected finding was somewhat impaired performance on two memory recall tests [110]. Consumption of a multispecies probiotic containing two Bifidobacterium spp and five Lactobacillus spp. by healthy participants produced a significant reduction in overall cognitive reactivity (negative thoughts) to sad mood [111].

A link between the gut and brain function is supported by additional human studies involving diseased or normal subjects. Many alcohol-dependent subjects have alterations in their intestinal permeability and gut microbiome. Increased intestinal permeability in these subjects was significantly associated with higher scores of depression, anxiety, and alcohol craving following 3 weeks of abstinence [112]. A placebo-controlled RCT of patients with major depressive disorder showed that a probiotic containing two Lactobacillus spp. plus Bifidobacterium bifidum produced a significant decrease in Beck Depression Inventory total scores, significant decreases in serum insulin levels and serum highsensitivity C-reactive protein (hs-CRP) concentrations in addition to a significant increase in plasma total glutathione concentrations [113]. A RCT of patients with Alzheimer's disease found that ingestion of a probiotic containing three Lactobacillus spp. plus Bifidobacterium bifidum significantly improved the mini-mental state examination scores, and produced significant changes in a range of metabolic parameters including plasma malondialdehyde, serum hsCRP and serum triglycerides [114]. Consumption of the prebiotic B-GOS, but not the prebiotic FOS, by healthy volunteers significantly reduced the salivary cortisol awakening response when compared to placebo [115].

Thus, these and similar studies provide the evidence that the gut microbiota can modulate the stress response and is also implicated in anxiety, depression and cognition. Therefore, the introduction of probiotic or symbiotic nutritional approaches are put forward by researches to prevent, delay, or ease neurological disorders in the future (see: [97]). However, the underlying mechanisms of these interactions are largely unclear and, at the present time, it is not possible to differentiate between the microbes involved.

\section{Conclusions}

The role of the human gut microbiota in health and disease is beginning to be understood. The composition of the gut microbiota is influenced by intrinsic mechanisms such as stress, and extraneous factors such as diet, prebiotics, probiotics, and drugs including PPIs and antibiotics. The dysbiosis of gut microbiota has been shown to be associated with IBD, IBS and depression.

It is clear that the gut microbiota is active, not passive, in its relationship with its host. Microbial metabolites (such as SCFAs) affect gut-brain signaling. The gut microbiota has a regulatory role on anxiety, mood, cognition and pain which is exerted via the gut-brain axis. In pregnancy dramatical 
changes of the maternal microbiota affects neonatal immune responses and maturation.

Ingestion of prebiotics or probiotics has been used to treat a range of conditions including constipation, allergic reactions and infections in infancy, and in patients with IBS. FMT is highly effective for treating recurrent Clostridium difficile infections and may be used more widely in the future for conditions such as metabolic syndrome.

Taken together, the effects of gut microbiome on health are multifaceted and researchers and health professionals try to educate consumers by including new scientific information into their practice, especially for benefits beyond digestive health. It is, therefore, expected that pre/probiotics will be combined with other nutritional compounds to achieve a more robust health effect. Moreover, it is expected that combining different research disciplines and utilization of new technological methodologies in the microbiome research may pave the way for developing evidence-based clinical interventions for health concerns of modern life.

Acknowledgements RKW is supported by a VIDI grant (016.136.308) from the Netherlands Organization for Scientific Research (NWO).

Author contributions MHM wrote this manuscript. Individual sections were corrected and complemented by RJMB, RAR, RKW, HJMH, MF. All co-authors reviewed and approved the manuscript before submission.

Conflict of interest MHM and ME are employees of DSM Nutritional Products, Kaiseraugst, Switzerland and as such no external funding was provided. HJMH received a research grand of DSM. RJMB, RAR, RKW, MF declare no conflict of interest.

Open Access This article is distributed under the terms of the Creative Commons Attribution 4.0 International License (http://creativeco mmons.org/licenses/by/4.0/), which permits unrestricted use, distribution, and reproduction in any medium, provided you give appropriate credit to the original author(s) and the source, provide a link to the Creative Commons license, and indicate if changes were made.

\section{References}

1. Peter S, Eggersdorfer M, van Asselt D, Buskens E, Detzel P, Freijer K, Koletzko B, Kraemer K, Kuipers F, Neufeld L, Obeid R, Wieser S, Zittermann A, Weber P (2014) Selected nutrients and their implications for health and disease across the lifespan: a roadmap. Nutrients 6(12):6076-6094. https://doi.org/10.3390/ nu6126076

2. Peter S, Saris WH, Mathers JC, Feskens E, Schols A, Navis G, Kuipers F, Weber P, Eggersdorfer M (2015) Nutrient Status Assessment in Individuals and Populations for Healthy AgingStatement from an Expert Workshop. Nutrients 7(12):1049110500. https://doi.org/10.3390/nu7125547

3. Troesch B, Biesalski HK, Bos R, Buskens E, Calder PC, Saris WH, Spieldenner J, Verkade HJ, Weber P, Eggersdorfer M (2015) Increased intake of foods with high nutrient density can help to break the intergenerational cycle of malnutrition and obesity. Nutrients 7(7):6016-6037. https://doi.org/10.3390/nu7075266
4. Peter S, Navis G, de Borst MH, von Schacky C, van Orten-Luiten ACB, Zhernakova A, Witkamp RF, Janse A, Weber P, Bakker SJL, Eggersdorfer M (2017) Public health relevance of drugnutrition interactions. Eur J Nutr 56(Suppl 2):23-36. https://doi. org/10.1007/s00394-017-1510-3

5. Ursell LK, Metcalf JL, Parfrey LW, Knight R (2012) Defining the human microbiome. Nutr Rev Suppl 1 Suppl 70:S38-44. https:// doi.org/10.1111/j.1753-4887.2012.00493.x

6. Gibson GR, Scott KP, Rastall RA, Tuohy KM, Hotchkiss A, Dubert-Ferrandon A, Gareau M, Murphy EF, Saulnier D, Loh G, Macfarlane S, Delzenne N, Ringel Y, Kozianowski G, Dickmann R, Lenoir-Wijnkook I, Walker C, Buddington R (2011) Dietary prebiotics: current status and new definition. Food Sci Technol Bull Funct Foods 7:1-19

7. Gibson GR, Hutkins R, Sanders ME, Prescott SL, Reimer RA, Salminen SJ, Scott K, Stanton C, Swanson KS, Cani PD, Verbeke K, Reid G (2017) Expert consensus document: The International Scientific Association for Probiotics and Prebiotics (ISAPP) consensus statement on the definition and scope of prebiotics. Nat Rev Gastroenterol Hepatol 14(8):491-502. https://doi.org/10.1038/nrgastro.2017.75

8. Sarbini SR, Rastall RA (2011) Prebiotics: metabolism, structure, and function. Funct Food Rev 3:93-106. https://doi. org/10.2310/6180.2011.00004 doi

9. Rakoff-Nahoum S, Foster KR, Comstock LE (2016) The evolution of cooperation within the gut microbiota. Nature 533(7602):255-259. https://doi.org/10.1038/nature17626

10. Nyangale EP, Mottram DS, Gibson GR (2012) Gut microbial activity, implications for health and disease: the potential role of metabolite analysis. J Proteome Res 11(12):5573-5585. https://doi.org/10.1021/pr300637d

11. Portune KJ, Beaumont M, Davila A-M, Tomé D, Blachier F, Sanz Y (2016) Gut microbiota role in dietary protein metabolism and health-related outcomes: The two sides of the coin. Trends Food Sci Technol 57:213-232. https://doi. org/10.1016/j.tifs.2016.08.011 doi

12. Verbeke KA, Boobis AR, Chiodini A, Edwards CA, Franck A, Kleerebezem M, Nauta A, Raes J, van Tol EA, Tuohy KM (2015) Towards microbial fermentation metabolites as markers for health benefits of prebiotics. Nutr Res Rev 28(1):42-66. https://doi.org/10.1017/S0954422415000037

13. Ramirez-Farias C, Slezak K, Fuller Z, Duncan A, Holtrop G, Louis P (2009) Effect of inulin on the human gut microbiota: stimulation of Bifidobacterium adolescentis and Faecalibacterium prausnitzii. Br J Nutr 101(4):541-550. https://doi. org/10.1017/S0007114508019880

14. Dewulf EM, Cani PD, Claus SP, Fuentes S, Puylaert PG, Neyrinck AM, Bindels LB, de Vos WM, Gibson GR, Thissen JP, Delzenne NM (2013) Insight into the prebiotic concept: lessons from an exploratory, double blind intervention study with inulin-type fructans in obese women. Gut 62(8):1112-1121. https://doi.org/10.1136/gutjnl-2012-303304

15. Vandeputte D, Falony G, Vieira-Silva S, Wang J, Sailer M, Theis S, Verbeke K, Raes J (2017) Prebiotic inulin-type fructans induce specific changes in the human gut microbiota. Gut 66(11):1968-1974. https://doi.org/10.1136/gutjnl-2016313271

16. Aguirre M, Jonkers DM, Troost FJ, Roeselers G, Venema K (2014) In vitro characterization of the impact of different substrates on metabolite production, energy extraction and composition of gut microbiota from lean and obese subjects. PLoS One 9(11):e113864. https://doi.org/10.1371/journal.pone.0113864

17. Moro G, Arslanoglu S, Stahl B, Jelinek J, Wahn U, Boehm G (2006) A mixture of prebiotic oligosaccharides reduces the incidence of atopic dermatitis during the first six months of 
age. Arch Dis Child 91(10):814-819. https://doi.org/10.1136/ adc. 2006.098251

18. Arslanoglu S, Moro GE, Boehm G (2007) Early supplementation of prebiotic oligosaccharides protects formula-fed infants against infections during the first 6 months of life. J Nutr 137(11):2420-2424

19. Arslanoglu S, Moro GE, Schmitt J, Tandoi L, Rizzardi S, Boehm G (2008) Early dietary intervention with a mixture of prebiotic oligosaccharides reduces the incidence of allergic manifestations and infections during the first two years of life. J Nutr 138(6):1091-1095

20. Arslanoglu S, Moro GE, Boehm G, Wienz F, Stahl B, Bertino E (2012) Early neutral prebiotic oligosaccharide supplementation reduces the incidence of some allergic manifestations in the first 5 years of life. J Biol Regul Homeost Agents 26(3 Suppl):49-59

21. Ivakhnenko OS, Nyankovskyy SL (2013) Effect of the specific infant formula mixture of oligosaccharides on local immunity and development of allergic and infectious disease in young children: randomized study. Pediatr Polska 88:398-404. https://doi. org/10.1016/j.pepo.2013.07.002

22. Kellow NJ, Coughlan MT, Reid CM (2014) Metabolic benefits of dietary prebiotics in human subjects: a systematic review of randomised controlled trials. Br J Nutr 111(7):1147-1161. https ://doi.org/10.1017/S0007114513003607

23. Cani PD, Lecourt E, Dewulf EM, Sohet FM, Pachikian BD, Naslain D, De Backer F, Neyrinck AM, Delzenne NM (2009) Gut microbiota fermentation of prebiotics increases satietogenic and incretin gut peptide production with consequences for appetite sensation and glucose response after a meal. Am J Clin Nutr 90(5):1236-1243. https://doi.org/10.3945/ajen.2009.28095

24. Hume MP, Nicolucci AC, Reimer RA (2017) Prebiotic supplementation improves appetite control in children with overweight and obesity: a randomized controlled trial. Am J Clin Nutr 105(4):790-799. https://doi.org/10.3945/ajcn.116.140947

25. Collado Yurrita L, San Mauro Martin I, Ciudad-Cabanas MJ, Calle-Puron ME, Hernandez Cabria M (2014) Effectiveness of inulin intake on indicators of chronic constipation; a metaanalysis of controlled randomized clinical trials. Nutr Hosp 30(2):244-252. https://doi.org/10.3305/nh.2014.30.2.7565

26. EFSA NDA Panel (EFSA Panel on Dietetic Products NaA (2015) Scientific Opinion on the substantiation of a health claim related to "native chicory inulin" and maintenance of normal defecation by increasing stool frequency pursuant to Article 13(5) of Regulation (EC) No 1924/2006. EFSA J 13 (1):3951, 12 pp. https:// doi.org/10.2903/j.efsa.2015.3951

27. Micka A, Siepelmeyer A, Holz A, Theis S, Schon C (2017) Effect of consumption of chicory inulin on bowel function in healthy subjects with constipation: a randomized, double-blind, placebo-controlled trial. Int J Food Sci Nutr 68(1):82-89. https ://doi.org/10.1080/09637486.2016.1212819

28. de Preter V, Vanhoutte T, Huys G, Swings J, Rutgeerts P, Verbeke K (2008) Baseline microbiota activity and initial bifidobacteria counts influence responses to prebiotic dosing in healthy subjects. Aliment Pharmacol Ther 27(6):504-513. https://doi.org/1 0.1111/j.1365-2036.2007.03588.x

29. Meijers BK, De Preter V, Verbeke K, Vanrenterghem Y, Evenepoel P (2010) p-Cresyl sulfate serum concentrations in haemodialysis patients are reduced by the prebiotic oligofructoseenriched inulin. Nephrol Dial Transpl 25(1):219-224. https://doi. org/10.1093/ndt/gfp414

30. Abrams SA, Griffin IJ, Hawthorne KM, Liang L, Gunn SK, Darlington G, Ellis KJ (2005) A combination of prebiotic shortand long-chain inulin-type fructans enhances calcium absorption and bone mineralization in young adolescents. Am J Clin Nutr 82(2):471-476
31. Whisner CM, Martin BR, Schoterman MH, Nakatsu CH, McCabe LD, McCabe GP, Wastney ME, van den Heuvel EG, Weaver CM (2013) Galacto-oligosaccharides increase calcium absorption and gut bifidobacteria in young girls: a doubleblind cross-over trial. Br J Nutr 110(7):1292-1303. https://doi. org/10.1017/S000711451300055X

32. Bhatia S, Prabhu PN, Benefiel AC, Miller MJ, Chow J, Davis SR, Gaskins HR (2015) Galacto-oligosaccharides may directly enhance intestinal barrier function through the modulation of goblet cells. Mol Nutr Food Res 59(3):566-573. https://doi. org/10.1002/mnfr.201400639

33. Akbari E, Asemi Z, Daneshvar Kakhaki R, Bahmani F, Kouchaki E, Tamtaji OR, Hamidi GA, Salami M (2016) Effect of probiotic supplementation on cognitive function and Metabolic Status in Alzheimer's disease: a randomized, double-blind and controlled trial. Front Aging Neurosci 8:256. https://doi.org/10.3389/fnagi .2016 .00256

34. Shoaf K, Mulvey GL, Armstrong GD, Hutkins RW (2006) Prebiotic galactooligosaccharides reduce adherence of enteropathogenic Escherichia coli to tissue culture cells. Infect Immun 74(12):6920-6928. https://doi.org/10.1128/IAI.01030-06

35. Konig J, Brummer RJ (2014) Alteration of the intestinal microbiota as a cause of and a potential therapeutic option in irritable bowel syndrome. Benef Microbes 5(3):247-261. https://doi. org/10.3920/BM2013.0033

36. Sender R, Fuchs S, Milo R (2016) Revised Estimates for the number of human and bacteria cells in the body. PLoS Biol 14(8):e1002533. https://doi.org/10.1371/journal.pbio.1002533

37. Flint HJ, Scott KP, Louis P, Duncan SH (2012) The role of the gut microbiota in nutrition and health. Nat Rev Gastroenterol Hepatol 9(10):577-589. https://doi.org/10.1038/nrgas tro.2012.156

38. Oleskin AV, Shenderov BA (2016) Neuromodulatory effects and targets of the SCFAs and gasotransmitters produced by the human symbiotic microbiota. Microb Ecol Health Dis 27:30971. https://doi.org/10.3402/mehd.v27.30971

39. Cox LM, Blaser MJ (2013) Pathways in microbe-induced obesity. Cell Metab 17(6):883-894. https://doi.org/10.1016/j. cmet.2013.05.004

40. Kim MH, Kang SG, Park JH, Yanagisawa M, Kim CH (2013) Short-chain fatty acids activate GPR41 and GPR43 on intestinal epithelial cells to promote inflammatory responses in mice. Gastroenterology 145(2):396-406 e391-310. https://doi. org/10.1053/j.gastro.2013.04.056

41. Bienenstock J, Kunze W, Forsythe P (2015) Microbiota and the gut-brain axis. Nutr Rev 73 Suppl 1:28-31. https://doi. org/10.1093/nutrit/nuv019

42. Hamer HM, Jonkers D, Venema K, Vanhoutvin S, Troost FJ, Brummer RJ (2008) Review article: the role of butyrate on colonic function. Aliment Pharmacol Ther 27(2):104-119. https ://doi.org/10.1111/j.1365-2036.2007.03562.x

43. Vanhoutvin SA, Troost FJ, Hamer HM, Lindsey PJ, Koek GH, Jonkers DM, Kodde A, Venema K, Brummer RJ (2009) Butyrateinduced transcriptional changes in human colonic mucosa. PLoS One 4(8):e6759. https://doi.org/10.1371/journal.pone.0006759

44. Vanhoutvin SA, Troost FJ, Kilkens TO, Lindsey PJ, Hamer HM, Jonkers DM, Venema K, Brummer RJ (2009) The effects of butyrate enemas on visceral perception in healthy volunteers. Neurogastroenterol Motil 21(9):952-e976. https://doi.org/10.11 $11 / \mathrm{j} .1365-2982.2009 .01324 . x$

45. Hamer HM, Jonkers DM, Vanhoutvin SA, Troost FJ, Rijkers G, de Bruine A, Bast A, Venema K, Brummer RJ (2010) Effect of butyrate enemas on inflammation and antioxidant status in the colonic mucosa of patients with ulcerative colitis in 
remission. Clin Nutr 29(6):738-744. https://doi.org/10.1016/j. clnu.2010.04.002

46. Konig J, Wells J, Cani PD, Garcia-Rodenas CL, MacDonald T, Mercenier A, Whyte J, Troost F, Brummer RJ (2016) Human Intestinal Barrier Function in Health and Disease. Clin Transl Gastroenterol 7(10):e196. https://doi.org/10.1038/ctg.2016.54

47. Karczewski J, Troost FJ, Konings I, Dekker J, Kleerebezem M, Brummer RJ, Wells JM (2010) Regulation of human epithelial tight junction proteins by Lactobacillus plantarum in vivo and protective effects on the epithelial barrier. Am J Physiol Gastrointest Liver Physiol 298(6):G851-859. https:// doi.org/10.1152/ajpgi.00327.2009

48. van Baarlen P, Troost F, van der Meer C, Hooiveld G, Boekschoten M, Brummer RJ, Kleerebezem M (2011) Human mucosal in vivo transcriptome responses to three lactobacilli indicate how probiotics may modulate human cellular pathways. Proc Natl Acad Sci U S A 108(Suppl 1):4562-4569. https://doi.org/10.1073/pnas.1000079107

49. Bron PA, Kleerebezem M, Brummer RJ, Cani PD, Mercenier A, MacDonald TT, Garcia-Rodenas CL, Wells JM (2017) Can probiotics modulate human disease by impacting intestinal barrier function? Br J Nutr 117(1):93-107. https://doi. org/10.1017/S0007114516004037

50. Mujagic Z, Ludidi S, Keszthelyi D, Hesselink MA, Kruimel JW, Lenaerts K, Hanssen NM, Conchillo JM, Jonkers DM, Masclee AA (2014) Small intestinal permeability is increased in diarrhoea predominant IBS, while alterations in gastroduodenal permeability in all IBS subtypes are largely attributable to confounders. Aliment Pharmacol Ther 40(3):288-297. https ://doi.org/10.1111/apt.12829

51. van Vliet MJ, Harmsen HJ, de Bont ES, Tissing WJ (2010) The role of intestinal microbiota in the development and severity of chemotherapy-induced mucositis. PLoS Pathog 6(5):e1000879. https://doi.org/10.1371/journal.ppat.1000879

52. Sundin J, Rangel I, Fuentes S, Heikamp-de Jong I, HultgrenHornquist E, de Vos WM, Brummer RJ (2015) Altered faecal and mucosal microbial composition in post-infectious irritable bowel syndrome patients correlates with mucosal lymphocyte phenotypes and psychological distress. Aliment Pharmacol Ther 41(4):342-351. https://doi.org/10.1111/apt.13055

53. Sundin J, Rangel I, Repsilber D, Brummer RJ (2015) Cytokine response after stimulation with key commensal bacteria differ in post-infectious irritable bowel syndrome (PI-IBS) patients compared to healthy controls. PLoS One 10(9):e0134836. https ://doi.org/10.1371/journal.pone.0134836

54. Li YT, Cai HF, Wang ZH, Xu J, Fang JY (2016) Systematic review with meta-analysis: long-term outcomes of faecal microbiota transplantation for Clostridium difficile infection. Aliment Pharmacol Ther 43(4):445-457. https://doi. org/10.1111/apt.13492

55. Konig J, Siebenhaar A, Hogenauer C, Arkkila P, Nieuwdorp M, Noren T, Ponsioen CY, Rosien U, Rossen NG, Satokari R, Stallmach A, de Vos W, Keller J, Brummer RJ (2017) Consensus report: faecal microbiota transfer-clinical applications and procedures. Aliment Pharmacol Ther 45(2):222-239. https ://doi.org/10.1111/apt.13868

56. Stolk RP, Rosmalen JG, Postma DS, de Boer RA, Navis G, Slaets JP, Ormel J, Wolffenbuttel BH (2008) Universal risk factors for multifactorial diseases: LifeLines: a three-generation population-based study. Eur J Epidemiol 2008 23(1):(1):67-74

57. Tigchelaar EF, Zhernakova A, Dekens JA, Hermes G, Baranska A, Mujagic Z, Swertz MA, Munoz AM, Deelen P, Cenit MC, Franke L, Scholtens S, Stolk RP, Wijmenga C, Feskens EJ (2015) Cohort profile: LifeLines DEEP, a prospective, general population cohort study in the northern Netherlands: study design and baseline characteristics. BMJ Open 5(8):e006772. https://doi.org/10.1136/bmjopen-2014-006772

58. Li Y, Oosting M, Smeekens SP, Jaeger M, Aguirre-Gamboa R, Le KTT, Deelen P, Ricano-Ponce I, Schoffelen T, Jansen AFM, Swertz MA, Withoff S, van de Vosse E, van Deuren M, van de Veerdonk F, Zhernakova A, van der Meer JWM, Xavier RJ, Franke L, Joosten LAB, Wijmenga C, Kumar V, Netea MG (2016) A functional genomics approach to understand variation in cytokine production in humans. Cell 167(4):1099-1110 e1014. https://doi.org/10.1016/j.cell.2016.10.017

59. Ter Horst R, Jaeger M, Smeekens SP, Oosting M, Swertz MA, Li Y, Kumar V, Diavatopoulos DA, Jansen AFM, Lemmers H, Toenhake-Dijkstra H, van Herwaarden AE, Janssen M, van der Molen RG, Joosten I, Sweep F, Smit JW, Netea-Maier RT, Koenders M, Xavier RJ, van der Meer JWM, Dinarello CA, Pavelka N, Wijmenga C, Notebaart RA, Joosten LAB, Netea MG (2016) Host and environmental factors influencing individual human cytokine responses. Cell 167(4):1111-1124 e1113. https ://doi.org/10.1016/j.cell.2016.10.018

60. Bonder MJ, Kurilshikov A, Tigchelaar EF, Mujagic Z, Imhann F, Vila AV, Deelen P, Vatanen T, Schirmer M, Smeekens SP, Zhernakova DV, Jankipersadsing SA, Jaeger M, Oosting M, Cenit MC, Masclee AA, Swertz MA, Li Y, Kumar V, Joosten L, Harmsen H, Weersma RK, Franke L, Hofker MH, Xavier RJ, Jonkers D, Netea MG, Wijmenga C, Fu J, Zhernakova A (2016) The effect of host genetics on the gut microbiome. Nat Genet 48(11):1407-1412. https://doi.org/10.1038/ng.3663

61. Imhann F, Bonder MJ, Vich Vila A, Fu J, Mujagic Z, Vork L, Tigchelaar EF, Jankipersadsing SA, Cenit MC, Harmsen HJ, Dijkstra G, Franke L, Xavier RJ, Jonkers D, Wijmenga C, Weersma RK, Zhernakova A (2016) Proton pump inhibitors affect the gut microbiome. Gut 65(5):740-748. https://doi.org/10.1136/gutjn 1-2015-310376

62. Schirmer M, Smeekens SP, Vlamakis H, Jaeger M, Oosting M, Franzosa EA, Horst RT, Jansen T, Jacobs L, Bonder MJ, Kurilshikov A, Fu J, Joosten LAB, Zhernakova A, Huttenhower C, Wijmenga C, Netea MG, Xavier RJ (2016) Linking the human gut microbiome to inflammatory cytokine production capacity. Cell 167(7):1897. https://doi.org/10.1016/j.cell.2016.11.046

63. Zhernakova A, Kurilshikov A, Bonder MJ, Tigchelaar EF, Schirmer M, Vatanen T, Mujagic Z, Vila AV, Falony G, VieiraSilva S, Wang J, Imhann F, Brandsma E, Jankipersadsing SA, Joossens M, Cenit MC, Deelen P, Swertz MA, Weersma RK, Feskens EJ, Netea MG, Gevers D, Jonkers D, Franke L, Aulchenko YS, Huttenhower C, Raes J, Hofker MH, Xavier RJ, Wijmenga C, Fu J (2016) LifeLines cohort s. Population-based metagenomics analysis reveals markers for gut microbiome composition and diversity. Science 352(6285):565-569. https://doi. org/10.1126/science.aad3369

64. Qin J, Li R, Raes J, Arumugam M, Burgdorf KS, Manichanh C, Nielsen T, Pons N, Levenez F, Yamada T, Mende DR, Li J, Xu J, Li S, Li D, Cao J, Wang B, Liang H, Zheng H, Xie Y, Tap J, Lepage P, Bertalan M, Batto JM, Hansen T, Le Paslier D, Linneberg A, Nielsen HB, Pelletier E, Renault P, Sicheritz-Ponten T, Turner K, Zhu H, Yu C, Li S, Jian M, Zhou Y, Li Y, Zhang X, Li S, Qin N, Yang H, Wang J, Brunak S, Dore J, Guarner F, Kristiansen K, Pedersen O, Parkhill J, Weissenbach J, Meta HITC., Bork P, Ehrlich SD, Wang J (2010) A human gut microbial gene catalogue established by metagenomic sequencing. Nature 464(7285):59-65. https://doi.org/10.1038/nature08821

65. Lynch SV, Pedersen O (2016) The human intestinal microbiome in health and disease. N Engl J Med 375(24):2369-2379. https ://doi.org/10.1056/NEJMra1600266

66. Faith JJ, Guruge JL, Charbonneau M, Subramanian S, Seedorf H, Goodman AL, Clemente JC, Knight R, Heath AC, Leibel RL, Rosenbaum M, Gordon JI (2013) The long-term stability of the 
human gut microbiota. Science 341(6141):1237439. https://doi. org/10.1126/science.1237439

67. David LA, Materna AC, Friedman J, Campos-Baptista MI, Blackburn MC, Perrotta A, Erdman SE, Alm EJ (2014) Host lifestyle affects human microbiota on daily timescales. Genome Biol 15(7):R89. https://doi.org/10.1186/gb-2014-15-7-r89

68. Fu J, Bonder MJ, Cenit MC, Tigchelaar EF, Maatman A, Dekens JA, Brandsma E, Marczynska J, Imhann F, Weersma RK, Franke L, Poon TW, Xavier RJ, Gevers D, Hofker MH, Wijmenga C, Zhernakova A (2015) The gut microbiome contributes to a substantial proportion of the variation in blood lipids. Circ Res 117(9):817-824. https://doi.org/10.1161/CIRCR ESAHA.115.306807

69. Chow J, Tang H, Mazmanian SK (2011) Pathobionts of the gastrointestinal microbiota and inflammatory disease. Curr Opin Immunol 23(4):473-480. https://doi.org/10.1016/j. coi.2011.07.010

70. Riviere A, Selak M, Lantin D, Leroy F, De Vuyst L (2016) Bifidobacteria and butyrate-producing colon bacteria: importance and strategies for their stimulation in the human gut. Front Microbiol 7:979. https://doi.org/10.3389/fmicb.2016.00979

71. Barbosa T, Rescigno M (2010) Host-bacteria interactions in the intestine: homeostasis to chronic inflammation. Wiley Interdiscip Rev Syst Biol Med 2(1):80-97. https://doi.org/10.1002/ wsbm. 48

72. Carding S, Verbeke K, Vipond DT, Corfe BM, Owen LJ (2015) Dysbiosis of the gut microbiota in disease. Microb Ecol Health Dis 26:26191. https://doi.org/10.3402/mehd.v26.26191

73. Fijlstra M, Ferdous M, Koning AM, Rings EH, Harmsen HJ, Tissing WJ (2015) Substantial decreases in the number and diversity of microbiota during chemotherapy-induced gastrointestinal mucositis in a rat model. Support Care Cancer 23(6):1513-1522. https://doi.org/10.1007/s00520-014-2487-6

74. Ulluwishewa D, Anderson RC, Young W, McNabb WC, van Baarlen P, Moughan PJ, Wells JM, Roy NC (2015) Live Faecalibacterium prausnitzii in an apical anaerobic model of the intestinal epithelial barrier. Cell Microbiol 17(2):226-240. https ://doi.org/10.1111/cmi.12360

75. Sokol H, Pigneur B, Watterlot L, Lakhdari O, BermudezHumaran LG, Gratadoux JJ, Blugeon S, Bridonneau C, Furet JP, Corthier G, Grangette C, Vasquez N, Pochart P, Trugnan G, Thomas G, Blottiere HM, Dore J, Marteau P, Seksik P, Langella P (2008) Faecalibacterium prausnitzii is an anti-inflammatory commensal bacterium identified by gut microbiota analysis of Crohn disease patients. Proc Natl Acad Sci U S A 105(43):16731-16736. https://doi.org/10.1073/pnas.0804812105

76. Willing B, Halfvarson J, Dicksved J, Rosenquist M, Jarnerot G, Engstrand L, Tysk C, Jansson JK (2009) Twin studies reveal specific imbalances in the mucosa-associated microbiota of patients with ileal Crohn's disease. Inflamm Bowel Dis 15(5):653-660. https://doi.org/10.1002/ibd.20783

77. Winter SE, Winter MG, Xavier MN, Thiennimitr P, Poon V, Keestra AM, Laughlin RC, Gomez G, Wu J, Lawhon SD, Popova IE, Parikh SJ, Adams LG, Tsolis RM, Stewart VJ, Baumler AJ (2013) Host-derived nitrate boosts growth of E. coli in the inflamed gut. Science 339(6120):708-711. https://doi. org/10.1126/science.1232467

78. Quevrain E, Maubert MA, Michon C, Chain F, Marquant R, Tailhades J, Miquel S, Carlier L, Bermudez-Humaran LG, Pigneur B, Lequin O, Kharrat P, Thomas G, Rainteau D, Aubry C, Breyner N, Afonso C, Lavielle S, Grill JP, Chassaing G, Chatel JM, Trugnan G, Xavier R, Langella P, Sokol H, Seksik P (2016) Identification of an anti-inflammatory protein from Faecalibacterium prausnitzii, a commensal bacterium deficient in Crohn's disease. Gut 65(3):415-425. https://doi.org/10.1136/gutjnl-2014-307649
79. Khan MT, Browne WR, van Dijl JM, Harmsen HJ (2012) How can Faecalibacterium prausnitzii employ riboflavin for extracellular electron transfer? Antioxid Redox Signal 17(10):14331440. https://doi.org/10.1089/ars.2012.4701

80. Sadaghian Sadabad M, von Martels JZ, Khan MT, Blokzij1 T, Paglia G, Dijkstra G, Harmsen HJ, Faber KN (2015) A simple coculture system shows mutualism between anaerobic faecalibacteria and epithelial Caco-2 cells. Sci Rep 5:17906. https:// doi.org/10.1038/srep17906

81. Steinert RE, Sadaghian Sadabad M, Harmsen HJ, Weber P (2016) The prebiotic concept and human health: a changing landscape with riboflavin as a novel prebiotic candidate? Eur J Clin Nutr 70(12):1461. https://doi.org/10.1038/ejen.2016.141

82. Bezirtzoglou E (1997) The intestinal microflora during the first weeks of life. Anaerobe 3(2-3):173-177. https://doi. org/10.1006/anae.1997.0102

83. Gritz EC, Bhandari V (2015) The human neonatal gut microbiome: a brief review. Front Pediatr 3:17. https://doi. org/10.3389/fped.2015.00017

84. Mueller NT, Bakacs E, Combellick J, Grigoryan Z, Dominguez-Bello MG (2015) The infant microbiome development: mom matters. Trends Mol Med 21(2):109-117. https ://doi.org/10.1016/j.molmed.2014.12.002

85. Rodriguez JM, Murphy K, Stanton C, Ross RP, Kober OI, Juge N, Avershina E, Rudi K, Narbad A, Jenmalm MC, Marchesi JR, Collado MC (2015) The composition of the gut microbiota throughout life, with an emphasis on early life. Microb Ecol Health Dis 26:26050. https://doi.org/10.3402/mehd.v26.26050

86. Koren O, Goodrich JK, Cullender TC, Spor A, Laitinen K, Backhed HK, Gonzalez A, Werner JJ, Angenent LT, Knight R, Backhed F, Isolauri E, Salminen S, Ley RE (2012) Host remodeling of the gut microbiome and metabolic changes during pregnancy. Cell 150(3):470-480. https://doi.org/10.1016/j. cell.2012.07.008

87. Gohir W, Whelan FJ, Surette MG, Moore C, Schertzer JD, Sloboda DM (2015) Pregnancy-related changes in the maternal gut microbiota are dependent upon the mother's periconceptional diet. Gut Microbes 6(5):310-320. https://doi. org/10.1080/19490976.2015.1086056

88. Wu HJ, Wu E (2012) The role of gut microbiota in immune homeostasis and autoimmunity. Gut Microbes 3(1):4-14. https ://doi.org/10.4161/gmic. 19320

89. Jimenez E, Marin ML, Martin R, Odriozola JM, Olivares M, Xaus J, Fernandez L, Rodriguez JM (2008) Is meconium from healthy newborns actually sterile? Res Microbiol 159(3):187193. https://doi.org/10.1016/j.resmic.2007.12.007

90. Moles L, Gomez M, Heilig H, Bustos G, Fuentes S, de Vos W, Fernandez L, Rodriguez JM, Jimenez E (2013) Bacterial diversity in meconium of preterm neonates and evolution of their fecal microbiota during the first month of life. PLoS One 8(6):e66986. https://doi.org/10.1371/journal.pone.0066986

91. Hu J, Nomura Y, Bashir A, Fernandez-Hernandez H, Itzkowitz S, Pei Z, Stone J, Loudon H, Peter I (2013) Diversified microbiota of meconium is affected by maternal diabetes status. PLoS One 8(11):e78257. https://doi.org/10.1371/journ al.pone. 0078257

92. Chu DM, Antony KM, Ma J, Prince AL, Showalter L, Moller M, Aagaard KM (2016) The early infant gut microbiome varies in association with a maternal high-fat diet. Genome Med 8(1):77. https://doi.org/10.1186/s13073-016-0330-z

93. Aagaard K, Ma J, Antony KM, Ganu R, Petrosino J, Versalovic J (2014) The placenta harbors a unique microbiome. Sci Transl Med 6(237):237ra265. https://doi.org/10.1126/scitranslm ed.3008599

94. Zheng J, Xiao X, Zhang Q, Mao L, Yu M, Xu J (2015) The Placental microbiome varies in association with low birth weight 
in full-term neonates. Nutrients 7(8):6924-6937. https://doi. org/10.3390/nu7085315

95. Gomez de Aguero M, Ganal-Vonarburg SC, Fuhrer T, Rupp S, Uchimura Y, Li H, Steinert A, Heikenwalder M, Hapfelmeier S, Sauer U, McCoy KD, Macpherson AJ (2016) The maternal microbiota drives early postnatal innate immune development. Science 351(6279):1296-1302. https://doi.org/10.1126/scien ce. $\operatorname{aad} 2571$

96. Cryan JF, Dinan TG (2012) Mind-altering microorganisms: the impact of the gut microbiota on brain and behaviour. Nat Rev Neurosci 13(10):701-712. https://doi.org/10.1038/nrn3346

97. Mohajeri MH, La Fata G, Steinert RE, Weber P (2018) Relationship between gut microbiome and brain function. Nutr Rev. https ://doi.org/10.1093/nutrit/nuy009

98. Sampson TR, Mazmanian SK (2015) Control of brain development, function, and behavior by the microbiome. Cell Host Microbe 17(5):565-576. https://doi.org/10.1016/j. chom.2015.04.011

99. Mayer EA, Tillisch K, Gupta A (2015) Gut/brain axis and the microbiota. J Clin Invest 125(3):926-938. https://doi. org/10.1172/JCI76304

100. Bercik P, Denou E, Collins J, Jackson W, Lu J, Jury J, Deng Y, Blennerhassett P, Macri J, McCoy KD, Verdu EF, Collins SM (2011) The intestinal microbiota affect central levels of brain-derived neurotropic factor and behavior in mice. Gastroenterology 141(2):599-609. https://doi.org/10.1053/j.gastr o.2011.04.052 (609, e591-593)

101. Bravo JA, Forsythe P, Chew MV, Escaravage E, Savignac HM, Dinan TG, Bienenstock J, Cryan JF (2011) Ingestion of Lactobacillus strain regulates emotional behavior and central GABA receptor expression in a mouse via the vagus nerve. Proc Natl Acad Sci U S A 108(38):16050-16055. https://doi.org/10.1073/ pnas. 1102999108

102. de Theije CG, Wu J, Koelink PJ, Korte-Bouws GA, Borre Y, Kas MJ, Lopes da Silva S, Korte SM, Olivier B, Garssen J, Kraneveld AD (2014) Autistic-like behavioural and neurochemical changes in a mouse model of food allergy. Behav Brain Res 261:265-274. https://doi.org/10.1016/j.bbr.2013.12.008

103. Desbonnet L, Clarke G, Shanahan F, Dinan TG, Cryan JF (2014) Microbiota is essential for social development in the mouse. Mol Psychiatry 19(2):146-148. https://doi.org/10.1038/mp.2013.65

104. Hsiao EY, McBride SW, Hsien S, Sharon G, Hyde ER, McCue T, Codelli JA, Chow J, Reisman SE, Petrosino JF, Patterson PH, Mazmanian SK (2013) Microbiota modulate behavioral and physiological abnormalities associated with neurodevelopmental disorders. Cell 155(7):1451-1463. https://doi.org/10.1016/j. cell.2013.11.024

105. Clarke G, Grenham S, Scully P, Fitzgerald P, Moloney RD, Shanahan F, Dinan TG, Cryan JF (2013) The microbiome-gut-brain axis during early life regulates the hippocampal serotonergic system in a sex-dependent manner. Mol Psychiatry 18(6):666-673. https://doi.org/10.1038/mp.2012.77
106. Bailey MT, Lubach GR, Coe CL (2004) Prenatal stress alters bacterial colonization of the gut in infant monkeys. J Pediatr Gastroenterol Nutr 38(4):414-421

107. O'Mahony SM, Marchesi JR, Scully P, Codling C, Ceolho AM, Quigley EM, Cryan JF, Dinan TG (2009) Early life stress alters behavior, immunity, and microbiota in rats: implications for irritable bowel syndrome and psychiatric illnesses. Biol Psychiatry 65(3):263-267. https://doi.org/10.1016/j.biopsych.2008.06.026

108. Tillisch K, Labus J, Kilpatrick L, Jiang Z, Stains J, Ebrat B, Guyonnet D, Legrain-Raspaud S, Trotin B, Naliboff B, Mayer EA (2013) Consumption of fermented milk product with probiotic modulates brain activity. Gastroenterology 144(7):1394-1401. https://doi.org/10.1053/j.gastro.2013.02.043 (1401, e1391-1394)

109. Messaoudi M, Lalonde R, Violle N, Javelot H, Desor D, Nejdi A, Bisson JF, Rougeot C, Pichelin M, Cazaubiel M, Cazaubiel JM (2011) Assessment of psychotropic-like properties of a probiotic formulation (Lactobacillus helveticus R0052 and Bifidobacterium longum R0175) in rats and human subjects. Br J Nutr 105(5):755-764. https://doi.org/10.1017/S0007114510004319

110. Benton D, Williams C, Brown A (2007) Impact of consuming a milk drink containing a probiotic on mood and cognition. Eur $\mathrm{J}$ Clin Nutr 61(3):355-361. https://doi.org/10.1038/sj.ejcn.16025 46

111. Steenbergen L, Sellaro R, van Hemert S, Bosch JA, Colzato LS (2015) A randomized controlled trial to test the effect of multispecies probiotics on cognitive reactivity to sad mood. Brain Behav Immun 48:258-264. https://doi.org/10.1016/j. bbi.2015.04.003

112. Leclercq S, Matamoros S, Cani PD, Neyrinck AM, Jamar F, Starkel P, Windey K, Tremaroli V, Backhed F, Verbeke K, de Timary P, Delzenne NM (2014) Intestinal permeability, gut-bacterial dysbiosis, and behavioral markers of alcohol-dependence severity. Proc Natl Acad Sci U S A 111(42):E4485-4493. https://doi. org/10.1073/pnas.1415174111

113. Akkasheh G, Kashani-Poor Z, Tajabadi-Ebrahimi M, Jafari P, Akbari H, Taghizadeh M, Memarzadeh MR, Asemi Z, Esmaillzadeh A (2016) Clinical and metabolic response to probiotic administration in patients with major depressive disorder: a randomized, double-blind, placebo-controlled trial. Nutrition 32(3):315-320. https://doi.org/10.1016/j.nut.2015.09.003

114. Akbari P, Fink-Gremmels J, Willems R, Difilippo E, Schols HA, Schoterman MHC, Garssen J, Braber S (2017) Characterizing microbiota-independent effects of oligosaccharides on intestinal epithelial cells: insight into the role of structure and size: structure-activity relationships of non-digestible oligosaccharides. Eur J Nutr 56(5):1919-1930. https://doi.org/10.1007/s0039 4-016-1234-9

115. Schmidt K, Cowen PJ, Harmer CJ, Tzortzis G, Errington S, Burnet PW (2015) Prebiotic intake reduces the waking cortisol response and alters emotional bias in healthy volunteers. Psychopharmacology 232(10):1793-1801. https://doi.org/10.1007/ s00213-014-3810-0 